\title{
Research on Countermeasure of Safe Navigation of Ship in Tidal Reach Zeyuan Shao ${ }^{1}$ and Wanzheng $\mathrm{Ai}^{2,{ }^{*}}$ \\ ${ }^{1}$ Marine College of Zhejiang Ocean University, Zhoushan 316000, P. R. China \\ ${ }^{2}$ Marine College of Zhejiang Ocean University, Zhoushan 316000, P. R. China \\ 1023874516@qq.com, ${ }^{b}$ aiwanzheng@163.com
}

\section{Keywords: Tidal reach; Ship; Navigation; Tidal current; Tide; Safety}

\begin{abstract}
Due to interaction of upstream runoff and open seas tidal current, the direction and velocity of water flow in tidal reach is variable. Plus non-periodic surge resulting from such factors as large rise and fall of the river bed and meteorological factors, water flow moves more complexly, so it is a section where many incidents occur. By analyzing kinetic characteristic of water flow in tidal reach, combining its own manipulating characteristics of the ship, this paper proposes measures to control navigation safety in tidal reach by controlling ship speed, reasonably distributing load, frequently measuring water level, controlling the speed of ship stream.
\end{abstract}

\section{Introduction}

Many shipping ports have tidal reach in the world. Many rivers in our country flow to the ocean eastward, seasonal variation of rainfall resulting from climate and short period water flow movement brought by effect of oceanic tide both influence hydrologic condition the these waterways. At some estuary regions with stronger tidal effect, main factor influencing hydrologic condition becomes tide. When analyzing safe region of ship navigation, multiple factors shall be considered. In addition to the influence of season change on hydrologic condition, the influence of tide shall also be referenced. Influenced by factors such as runoff, tidal current, wave, wind, even storm tide, tidal reach water flows highly nonlinearly. Oceanic tide wave can move upstream to long distance. During Changjiang River low water major tide, the boundary of tide zone can arrive near Datong more than $600 \mathrm{~km}$ far from the estuary[1-2]. Due to complexity of tidal reach water flow, tidal reach is often a section where many incidents occur. For example, self-submersion of ship in Changjiang Jiangsu section in 2015. "Wanshenzhou 7" ship turned upside down during trial navigation in Fujiangsha north waterway of Changjiang. The region incident occurring is a river section with tide, where water is very deep and flows very quickly, it is very difficult to search for and rescue it underwater. The ship in the incident turned upside down, and it always moved and sunk slowly due to influence of external factors, normal rescuing ship couldn't approach it to work, intensifying difficulty of rescue. Around research on method of simulating tidal reach water flow, related experts at home and abroad conducted some researches, for example, Haiyun Cheng et (1997) established linear diffusion wave equation water level analytic solution model considering influence of back flow and literal flow[3]; Saavedrad et (2003) analyzed tidal reach water flow issue through kinetic wave[4]; Long Jiang et(2007) constructed internal boundary condition equation set overall solution at the connection of one and two dimension[5]. Researches on tidal reach water flow of related experts using mathematic model achieved some results, but this only has certain guiding significance to safe navigation issue of ship in tidal reach. It is found by referring materials on CNKI that there is very few research on safe navigation issue of ship in tidal reach. Hong Zhao et (2015) proposed that when the ship navigates in tidal reach, the influence of tidal current on the stopping distance and delay of the ship has important influence on dodging effect.[6]. Jiaqiang Shao et(2015) proposed that before the ship enters or exits estuary the influence of tidal current on the ship shall be given full consideration, such as the influence of water level difference, "funneling effect" on the ship[7]. When they researched safe navigation issue of tidal reach, they considered more the influence of tidal current on the ship itself, not influence on the ship itself, for example, the speed, load distribution of the ship in a section. So, the influence of tidal reach tidal 
current on safe navigation of ship and on the ship itself needs to be researched deeply. By analyzing formation and some hydrodynamic characteristics of tidal reach, starting from some characteristics of the ship itself, this paper deeply analyzes how the ship to safely navigate in tidal reach[8-9].

\section{Formation of tidal reach}

Tidal reach is a section of river from estuary to tide zone boundary, and tide is the main factor form tidal reach. So we can describe formation tidal reach by analyzing formation of tide. Tide will influence water level and flow rate of tidal reach. Periodic movement of sea surface is called tide. Tide rise and fall is a periodic movement actually, rise of sea surface is egre, sea surface reaching max height is high tide, fall of sea surface is add tide, sea surface reaching min height is low tide. While sea water has periodic phenomenon, it also flows horizontally periodically, called tidal current. Any a water mass point on the earth surface is influenced by inertia centrifugal force of earth rotation, gravity and celestial gravitation. Now tide science develops very quickly, some useful tide theories appearing. 2 hypothesis of equilibrium tide theory simplifies the problem more. Formation oftide is shown in Fig.1.

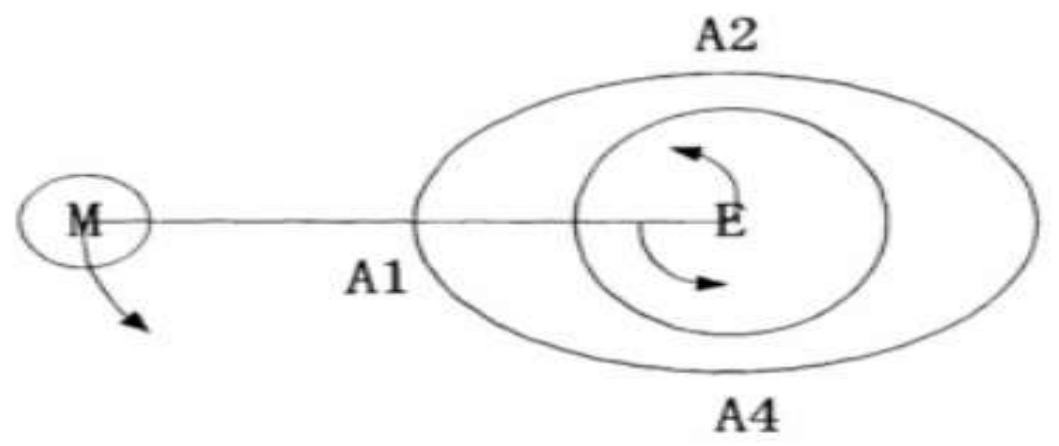

A3

Figure 1. Lunar tide ellipsoid

Fig. 1 supposes that the moon is a lunar tide ellipsoid with declination of $0, \mathrm{E}$ is earth pole, A1, A2, A3, A4 represent 4 positions of any a point on earth surface in earth rotation. The long axis of tide ellipsoid is in the connection line of centers of the earth and moon.

When the earth begins to rotate to A1, the moon is at upper centmination at the point, now sea level of the earth rises to the highest point, the first local high tide on the day appears; when the earth rotates to A2, now sea level will fall to the lowest, the first local low tide on the day appears; when the earth rotates to $\mathrm{A} 3$, the moon is at lower centmination, now sea level will rise to the highest point for second time, now second local high tide on the day appears; when the moon rotates to A4, now sea level falls to the lowest point for second time, the second low tide appears.

Inequality of tide includes three kinds: diurnal inequality of tide, semi-menstrual inequality, parallax inequality of tide. The height of two high tides or two low tides or time interval between adjacent high tide and low tide occurring on the same lunar day are unequal, which is called diurnal inequality of tide. From full moon to last quarter, from last quarter to new moon, the same repeats. Obviously, tide difference varies at the period of half synodic month, which is called semi-menstrual inequality of tide. Because the moon revolves around the earth along ellipse route, the earth is at one of focal point of the ellipse, when the moon is at near earth point, tide generating force here is larger by $40 \%$ compared with far earth point. Inequality of tide resulting from variation of distance between the earth and moon is called parallax inequality of tide[10-11].

\section{Hydrological characteristics of tidal reach}

Transitional river section between the river and sea is tidal reach which is influenced by forces of the river and sea, and two forces interact in the region. The two forces keep their own movement characteristics and trail either in time or in space. The two forces include various factors, and these factors also combine their own movement, so hydrological situation of this kind of river section is 
more dangerous compared with any of separate river and sea, with distinct characteristics. In the same river, the tidal current boundary and tide zone boundary of tidal reach are movable, moving back and forth in a fixed region, and the moving region is transitional region. When there is flood, if a small tide happens to occur, the directions of water flow and wind are the same, if the movement force of river is stronger, then the tidal current boundary and tide zone boundary will vary downward very obviously; during dry period, there is a large tide, the directions of water flow and wind are different, if movement force of the river is weaker, then tidal current boundary and tide zone boundary will vary downward very obviously, moving up dramatically[12-13]. Hydrological characteristics of tidal reach mainly includes three: runoff, tide and tidal current. Analyze the data sheet of hydrology website. Runoff data of Datong Station of our country can basically reflect the information on runoff of Changjaing River section. From 1953 to 1998, annual average runoff is $8980 \times 108$, and monthly average runoff in July is the largest, accounting for about $14.94 \%$ total of the year; monthly average runoff in February is the smallest, only accounting for $3.12 \%$ annual runoff. Analyzing tide of Changjiang river section, the tide type in Changiiang estuary is abnormal semi-diurnal shallow sea tide which can rise and fall twice within a day, with stronger diurnal inequality. Yearly max tide level usually occurs when three or two of typhoon, astronomical tide and upstream large flood encounter, among them, the influence of typhoon is larger. Analyzing tidal current of Changjiang river section, tidal current influences river section greatly, typically, in flood season ebb tide in main channel flows quickly, lasts long time, so it is main driving force to form main channel riverbed morphology of river section.

\section{Safe navigation control of ship in tidal reach}

\section{Control ship speed}

Fig. 2 shows that in tidal reach tidal current moves violently. The biggest influence of current on ship manipulation is to make ship drift. The ship navigates in water flow as shown in Fig. 1, suppose that the included angle of the navigation direction of the ship and Y axis is $\alpha$,ship speed is Us, velocity of flow is Uc,the included angle of current and $Y$ axis is $\beta$. If navigation distance of the ship in the direction of $\mathrm{Y}$ axis is $\mathrm{S}$,then the drift of the ship in the direction of $\mathrm{X}$ axis is $\Delta \mathrm{B} 1$

The speed of ship in $\mathrm{X}$ axis when moving is

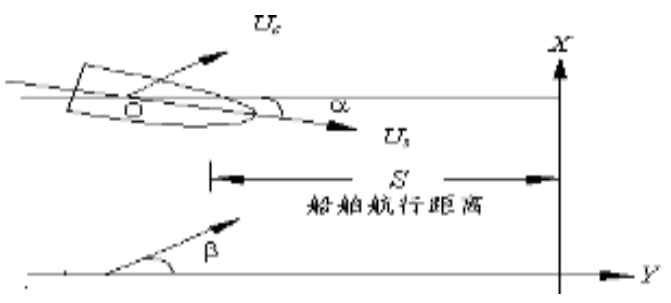

$\mathrm{Ux}=\mathrm{UC} \sin \beta+\mathrm{Us} \sin \alpha$

The speed of ship in $\mathrm{Y}$ axis when moving is

$\mathrm{Uy}=\mathrm{UC} \cos \beta+\mathrm{Uscos} \alpha$

The data of drift of ship resulting from current is

$\Delta \mathrm{B} 1=\mathrm{Ux} \times \mathrm{T}=\times \mathrm{S}(/ \mathrm{UC} \cos \beta+\mathrm{Us} \cos \alpha /)$

It can be found from equation (3)that the larger the ship speed Us is, the larger be drift,of ship resulting from current is. So ship speed will drop constantly by lowering the drift data of ship in tidal reach. Suppose that ship speed is far higher than normal, then declining quantity of ship speed will also increase constantly, easily resulting in safety incidents such as stranding in tidal reach.

\section{Reasonably distribute load, reduce inclination}

When the ship navigates in tidal reach, because water is deep and flow rapidly, and due to influence of strong bevel current during navigation, tidal current will produce diving force on the ship in right and left direction. Because of uneven area distribution at the bow and stern, there is larger current pressure around stern, resulting in the influence of current on the ship transferring to middle-rear part of the ship, and pivoting point is about $1 / 3$ from the bow during navigation, 
producing the moment of the bow in the direction of current. Because multiple parts of the ship receive different lateral force of water flow, the ship inclines badly, in order to reduce inclination of the ship, it is more important to appropriately distribute load. When advancing, the stability GM value is required neither too large nor too small. Too large GM value will result in increase of steering frequency of ship, also result in staff onboard at uncomfortable state. Suppose that GM value is vary small, lack of stability may occur resulting in capsized ship. Before the ship enters tidal reach, left and right ballast water of ship shall be adjusted, and GM value is controlled to make the ship as stable as possible.

\section{Measure water level frequently}

There are many shallow water zone in tidal reach, and most shallow water zones have sludge, if you want to pass through shallow water zone, you need to refer materials in advance to calculate the height of tide in the route passed through, then adjust the load and waterline. If you plan to make the ship pass through the segment safely, you need to collect material about local tidal movement, comprehensively knowing heading and speed of the ship, fully recognizing influence of tidal movement on ship navigation, all starts from safety. River depth of tidal reach varies constantly, it is dynamic data, so it cannot be judged according to fixed data. Water level variation and waterline variation of ship shall be observed at any time, if waterline of the ship is very high, you need to adjust load in time or wait for tide itself moving, you must pass shallow water zone of tidal reach when water level is safe [14-16].

\section{Control the speed of ship stream}

Considering tidal characteristics of tidal reach, influence of tide on navigation shall be considered comprehensively, when the load on the ship is larger, and power of power device of the ship is smaller, if you encounter a large tide, you should lower ship speed urgently, so when passing small tide zone, you should be prepared for large tide. Even if the ship with smaller power runs very quickly, influence of small power ship on safe navigation of ship during flow back. Marine administration shall pay attention to ship entering estuary during falling tide of tidal surge, recording tonnage, max speed of ship in detail. If you want the ship to enter port at this time, shall have those ships with large power, high speed and low waterline enter first, such as passenger liner, container vessels. The marine administration can establish a database accordingly. It shall arrange those ships running slowly, with small horsepower to enter port when navigation pressure is smaller, river flows rapidly, so as to avoid influence on speed of ship running in whole channel.

\section{Conclusion}

The condition of water flow in tidal reach is complex, velocity of water flow is inconstant back and forth. When ship navigate in tidal reach, some ship related incidents occur very possibly, such as ship collision. Dangerous incidents such as stranding, inclination also occur easily. Starting from formation of tidal reach and some hydrological features, as well as some characteristics of the ship itself, some effective suggestions on how the ship to navigate in tidal reach safely are proposed [17-18].

\section{Reference}

[1] Li Zhonggang, Research on Defining Method of Tidal Reach Bridge Waters[J]Wuhan University of Technology,2010.04.

[2] Wang Zhenhong, Zhang Hongqing, Jiang Xinpei, Liu Lihua, Tidal Reach Water Power Simulation Experiment [J] Water Science and Engineering Technology ,2005.01.

[3] Cheng Haiyun, Rui Xiaofang, Ji Xuewu, Linear Diffusion Wave Equation Analytic Solution and Its Application in Water Level Prediction [J] Water Science Progress, 1997.06.

[4] SAAVEDRA I,LÓPEZ J L, GARCÍA-MARTÍNEZ R. Dynamic wave study of flow in tidal channel system 205of San Juan River [J]. Journal of Hydraulic Engineering, 2003, 129(7):519-526.

[5] Long Jiang, Li Shiyu, Finite Element Calculating Method of 1D, 2D Simultaneous Solution of 
Water Power in Zhujiang Estuary [J] Hydrodynamics Research and progress (Collection A), 512-519.215.

[6] Zhao Hong, Zhao Jinbao, Analysis of Influence of Tidal Current on Ship Manipulation [J] China Waterborne Transportation 2015. 02

[7] Shao Jiaqiang, Discussion of Tidal Current of Shanghai Port and Its Influence on Shipping [J] Zhujiang Waterborne Transport 2015. 05

[8] Chi Hongfu, Ding Tianming, Research on Navigation Safety of Cross Channel [J] China Waterborne Transportation, 2013. 08

[9] Knowledge of Tide, Internet Document Resource, 2015. 02

[10] Guo Yu, Zhang Jiping, Dai Ran, Nautical Navigation, Dalian Maritime University Press Dalian, 2014. 08

[11] Tides and currents, Internet Document Resource, 2012.09.

[12] Sun Xiuling, Frequency Combination Method for Calculation of Design Water Level at Tidal Reach Bridge[J]Shandong Transportation Science and Technology,1998,05.

[13] Ye Lingyun, Constructing Prediction Model of Coastal Peak Water Level at Lingjiang with SPSS Regression Analysis [J] Water Conservancy Planning and Design 2014. 05

[14] Wang Fajun, Dong Fang, Discussion on ECDIS Based on Real-time Report and Prediction of Tide, Collection of Thesis on Current Situation and Development Trend of Navigation Technology 2001, 2001. 06

[15] Wu Yongjun, Ling Yuan, Wang Xin, Discussion on Application of ECDIS in Navigation in Changjiang Waters [J] Tianjin Navigation, 2011, 12

[16] Wu Yongjun, Primary Exploration of Research on Application of ECDIS in Navigation in Changjiang Waters, Thesis Collection for Fujian Ocean Society Annual Academic Conference 2012, 2013, 01

[17] Terrain simulation based on ther eeursive Refinement of ridge-line. ChibaN,MuraokaK,YaegashiK, etal. Proeof the Seeond Int Conf on Computer-Aided Design and Computer GraPhies . 1991

[18] Spawning habitat rehabilitation- I . Conceptual approach and methods. Wheston Joseph M,Pasternack Gregory B,Merz Joseph E. Intl. J. River Basin Management . 2004 